\title{
Numerical Simulation of Shear Behavior and Permeability Evolution of Rock Joints with Variable Roughness and Infilling Thickness
}

\author{
Jingyi Cheng $\mathbb{D},{ }^{1,2}$ Hongwei Zhang $\left(\mathbb{D},{ }^{2,3}\right.$ and Zhijun Wan $\mathbb{D}^{2}$ \\ ${ }^{1}$ State key Laboratory of Coal Resources and Safe Mining, China University of Mining and Technology, Xuzhou, \\ Jiangsu 221116, China \\ ${ }^{2}$ Key Laboratory of Deep Coal Resource Mining (CUMT), Ministry of Education of China, School of Mines, \\ China University of Mining and Technology, Xuzhou, Jiangsu 221116, China \\ ${ }^{3}$ Department of Energy and Mineral Engineering, EMS Energy Institute, and G3 Center, The Pennsylvania State University, \\ University Park, PA 16802, USA
}

Correspondence should be addressed to Hongwei Zhang; cumtkyzhw@cumt.edu.cn and Zhijun Wan; zhjwan@cumt.edu.cn

Received 6 July 2018; Accepted 13 November 2018; Published 13 December 2018

Guest Editor: Wen Wang

Copyright (C) 2018 Jingyi Cheng et al. This is an open access article distributed under the Creative Commons Attribution License, which permits unrestricted use, distribution, and reproduction in any medium, provided the original work is properly cited.

\begin{abstract}
The mechanical properties and permeability evolution of sand-infilled rock joints during the shear process is an important issue in rock engineering, such as it pertains to hydraulic fractures filled with proppant. Shear can disrupt the preexisting hydraulic and mechanical equilibrium conditions, thus affecting fluid flow. In this study, we simulate the shear behavior of rock joints with variable roughness and sand infilling thickness using the discrete element code PFC2D. Rock joint roughness is evaluated by the joint roughness coefficient (JRC), and sand infilling thickness is evaluated by a thickness ratio (i.e., ratio of infill thickness to rock height) ranging from 0.02 to 0.20 . The results show that peak shear strength decreases with the thickness ratio in a relation that can be expressed by a hyperbolic function. We also measure the permeability evolution during shearing and find that the permeability of infilled rock joints increases with both the thickness ratio and JRC.
\end{abstract}

\section{Introduction}

The mechanical and hydraulic properties of rock joints are of great significance in rock engineering, including near-field modeling of activated faults [1-3], petroleum, shale, and geothermal reservoirs [4-9]. Shear stimulation of existing fracture networks is considered a method for permeability enhancement in geothermal systems [10-12]. Similar to fault zones (Figures 1(a) and 1(b)) with continuous infilled gouge layers $[13,14]$, weathered joints (Figure $1(\mathrm{c})$ ) are generally filled with undeformed minerals, which can significantly influence the mechanical properties and permeability of rock masses [15]. The shear behavior and permeability of filled discontinuities in rock are determined by several parameters, including the infill thickness and joint surface roughness [16-18]. Although the influence of joint roughness and infill thickness on rock mechanics has been studied previously, the coupled effect of these parameters on the mechanical behavior and permeability evolution of filled discontinuities is rarely reported.

Shear failure occurs when a frictional threshold value is reached. A sand-infilled rock joint can dramatically reduce the shear failure strength of a rock mass, and the infilled materials can dominate the shear behavior of intact rock due to its relatively low frictional properties [19-22]. The infill thickness plays a vital role in estimating the mechanical behavior of a rock mass. Specifically, a thicker infill implies a smaller peak shear strength $[23,24]$. Several models have been proposed to predict the peak shear strength of infilled joints by considering the ratio of infill thickness $(t)$ to the height of an idealized (i.e., regular or planar) joint wall asperity (a) [25-29]. In these models, shear strength decreases with $t$ prior to reaching the critical value $t / a$. However, natural rock joints commonly have undulating surfaces, 

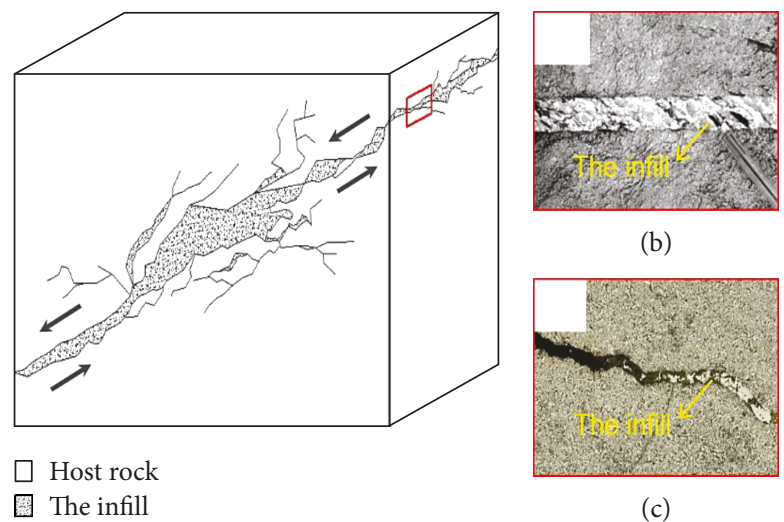

(b)

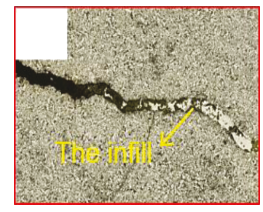

(c)

(a)

Figure 1: (a) 3D schematic diagram of the infill in a rock mass during shearing. (b) Photograph of a fault with internal alignment of infilled materials (modified from Kirkland et al. [66]). (c) Photograph of a joint filled with clay minerals.

and the resistance of the roughness may pose a significant difference to that of a hypothetical smooth surface. Hence, it is difficult to estimate the shear strength of natural joints because a reasonable t/a ratio is not easily determined.

In order to characterize natural joint roughness, Barton [30] introduced the joint roughness coefficient (JRC), which varies from 0 to 20 , corresponding to the smoothest to the roughest joint surfaces. Based on the JRC, Barton and Choubey [31] established an empirical law of rock joint friction to estimate the shear strength of rock joints. Numerous subsequent studies have been conducted to investigate shear strength criteria [32-35], mechanical behavior [36-39], and porosity and/or permeability evolution of infilled joints [40-43]. Coupled shear-flow experiments of a single rock joint have also been performed to study the effect of joint shear deformation on the permeability evolution of rock joints [44-52]. Specifically, Ye et al. conducted a series of novel shear stimulation experiments to probe the fundamental principle of permeability enhancement in rock joints. The experimental results demonstrate that dilatant shear deformation and cracks propagation are two crucial and integral mechanisms for permeability creation in rock joints.

Fluid flow through a single rough fracture varies with shear displacement. More specifically, the permeability of a rock mass decreases with loading stress and increases with shear-induced dilation. However, research on the coupled effects of JRCs and infill thickness on permeability evolution is underreported in the literature. In this study, we numerically simulate the shearing process of infilled rock joints using particle flow code (PFC) software. The paper is organized as follows: the distinct element numerical method and material parameters are introduced in Section 2, the simulation procedure is illustrated in Section 3, and results and discussion are presented in Section 4. Finally, several important conclusions are drawn in Section 5.

\section{Numerical Method and Material Parameters}

2.1. Description of DEM and PFC2D. The distinct element method (DEM) is based on solving Newton's second law of motion for an assembly of particles with a predefined constitutive model applied to the grain-grain contacts [53]. Particle flow code 2D (PFC2D) is a two dimensional program based on DEM theory $[54,55]$. In PFC2D, particles are idealized as rigid particles that interact with one another at their contacts.

The calculation cycle in PFC2D is a time-stepping algorithm, and the contact force is updated by the forcedisplacement law. When particles come into contact, the contact forces are calculated as a function of relative displacements and specified stiffness. The linear relationships can be expressed as follows:

$$
\begin{aligned}
F_{i}^{n} & =K_{n} U_{n} n_{i}, \\
\Delta F_{i}^{s} & =K_{s} \Delta U_{i}^{s},
\end{aligned}
$$

where $F_{i}^{n}$ represents the total normal force, $K_{n}$ is the normal stiffness, $U_{n}$ is the total normal displacement, $n_{i}$ is the unit normal vector to the contact plane, $\Delta F_{i}{ }^{s}$ is the relative shear force, and $K_{s}$ and $\Delta U_{i}^{s}$ are the shear stiffness and relative shear displacement, respectively.

For sand-infilled discontinuities, we only consider the frictional parts of particles. Thus, in the direct shear numerical simulation, shear slip occurs when the iteratively checked contact force exceeds the maximum allowable shear contact force.

$$
F_{i}^{s} \geq F_{\max }^{s}=\mu\left|F_{i}^{n}\right|
$$

where $\mu$ represents the friction coefficient at the contact.

2.2. Contact Bond Model. The numerically simulated specimens consist of two groups, intact rock and infill, represented as yellow and red particles, respectively, in Figures 2(a) and 2(b). An intact rock with joints is represented as a heterogeneous material of cemented grains. A real cement is present in sedimentary rock, while granular interlock in crystalline rock (e.g., granite) can be considered the notional cement. A parallel bond provides the 


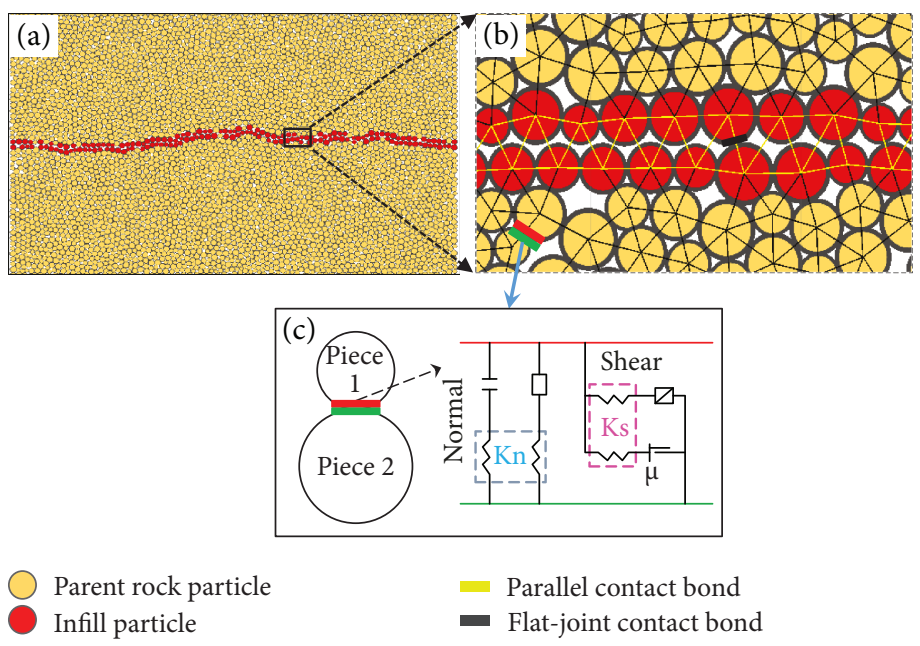

FIGURE 2: Infilled joint and contact models. (a) Numerically simulated specimen with an infilled joint. The yellow and red particles represent the intact rock and infill, respectively. (b) Magnified picture of Figure 2(a). (c) Components of the linear parallel contact bond model.

mechanical behavior of a cement-like material substance between two contacting particles [56]. The parallel bond component acts in parallel with the linear component and establishes an elastic interaction between the pieces (Figure 2(c)). Parallel bonds, which can transmit both force and moment between pieces, have been successfully employed in estimating the mechanical behavior of rocks [57-59].

2.3. Permeability Enhancement Model. A sigmoidal logarithmic function is employed to illustrate the permeability versus shear displacement curve [60].

$$
k=\frac{k_{\max }}{\left[1+\exp \left(\ln (n) \cdot\left(1-2 \cdot\left(d-d_{5}\right) /\left(d_{95}-d_{5}\right)\right)\right)\right]},
$$

where $k_{\max }$ is the maximum increment in permeability, $k$ is the permeability change, $d$ is the shear displacement, $n$ is a constant related to the intrinsic property of the materials, and $d_{5}$ and $d_{95}$ are shear displacements at which $5 \%$ and $95 \%$ of the total permeability enhancement has occurred, respectively.

According to equation (3), the relative difference in permeability is

$$
\frac{k}{k_{0}}=\frac{k_{\max } /\left[1+\exp \left(\ln (n) \cdot\left(1-2 \cdot\left(\varepsilon-\varepsilon_{5}\right) /\left(\varepsilon_{95}-\varepsilon_{5}\right)\right)\right)\right]}{k_{0}} .
$$

Combining equations (3) and (4), we obtain

$$
\phi=\frac{\phi_{\max }}{\left[1+\exp \left(\ln (n) \cdot\left(1-2 \cdot\left(\varepsilon-\varepsilon_{5}\right) /\left(\varepsilon_{95}-\varepsilon_{5}\right)\right)\right)\right]} .
$$

Equation (4) can be rearranged as

$$
\begin{aligned}
\frac{k}{k_{0}}= & {\left[1+\frac{\phi_{\max }}{1+\exp \left(\ln (n) \cdot\left(1-2 \cdot\left(\varepsilon-\varepsilon_{5}\right) /\left(\varepsilon_{95}-\varepsilon_{5}\right)\right)\right)}\right.} \\
& \left.-\frac{\phi_{\max }}{1+\exp \left(\ln (n) \cdot\left(1-2 \cdot\left(\varepsilon_{0}-\varepsilon_{5}\right) /\left(\varepsilon_{95}-\varepsilon_{5}\right)\right)\right)}\right]^{3},
\end{aligned}
$$

where $k_{0}$ is the initial permeability, $\varepsilon$ is the shear strain, $\varepsilon_{5}$ and $\varepsilon_{95}$ are shear strains at which $5 \%$ and $95 \%$ of the total permeability has occurred, respectively, and $n$ equals 11.0.

2.4. Material Parameters. As shown in Figure 2(a), the numerically simulated granite specimen consists of upper and the lower halves and the infilled material (assumed as nonbonded to which a zero bond strength is assigned). The elastic behavior of the granular assembly is represented by assigning an effective modulus and normal-to-shear stiffness ratio to the grain-to-grain contacts. The average, maximum, and minimum ball radius were $3.9 \times 10^{-3} \mathrm{~mm}, 3.0 \times$ $10^{-3} \mathrm{~mm}$, and $4.8 \times 10^{-3} \mathrm{~mm}$, respectively. Each ball had at least three contacts with other neighboring balls, and balls without contacts were algorithmically identified as floaters. Different material parameters, including the normal-toshear stiffness ratio, calibrated Young's modulus, and uniaxial compressive strength (UCS) are listed in Table 1.

\section{Numerical Simulation Design}

The direct shear configuration consists of two sets of densely packed particles of nonuniform size and a gouge sandwiched between them (Figure 3(a)). The two sets represent the upper and lower rocks, respectively. In the DEM modelling, 4811 particles were packed into a rectangular box with a length of $60 \mathrm{~mm}$ and height of $40 \mathrm{~mm}$. The profiles of the infilled assembly were attributed by fitting five typical joint roughness curves [31]. In the numerical simulation of the shear tests, five groups of specimens (i.e., $\mathrm{T} 1$ to $\mathrm{T} 5$ ) were 
TABLE 1: Mechanical and physical parameters of granite and infill.

\begin{tabular}{lccc}
\hline & Granite & Infilled sand & Unit \\
\hline Density & 2600 & 2000 & $\mathrm{~kg} / \mathrm{m}^{3}$ \\
Radius & $3 \times 10^{-3} \sim 4.8 \times 10^{-3}$ & $3 \times 10^{-3} \sim 4.8 \times 10^{-3}$ & $\mathrm{~mm}$ \\
Average radius & $3.9 \times 10^{-3}$ & $3.9 \times 10^{-3}$ & $\mathrm{~mm}$ \\
Interparticle friction & 0.577 & 0.577 & $\mathrm{~N} / \mathrm{A}$ \\
Normal-to-shear stiffness ratio & 2.5 & 5 & $\mathrm{GPa}$ \\
Parallel bond effective modulus & 5 & 0 & $\mathrm{MPa}$ \\
Parallel bond tensile strength & 60 & 0 & $\mathrm{MPa}$ \\
Parallel bond cohesion & 120 & 0 & $\mathrm{GPa}$ \\
Calibrated Young's modulus & 30.0 & 0 & $\mathrm{MPa}$ \\
Calibrated UCS & 181 & &
\end{tabular}

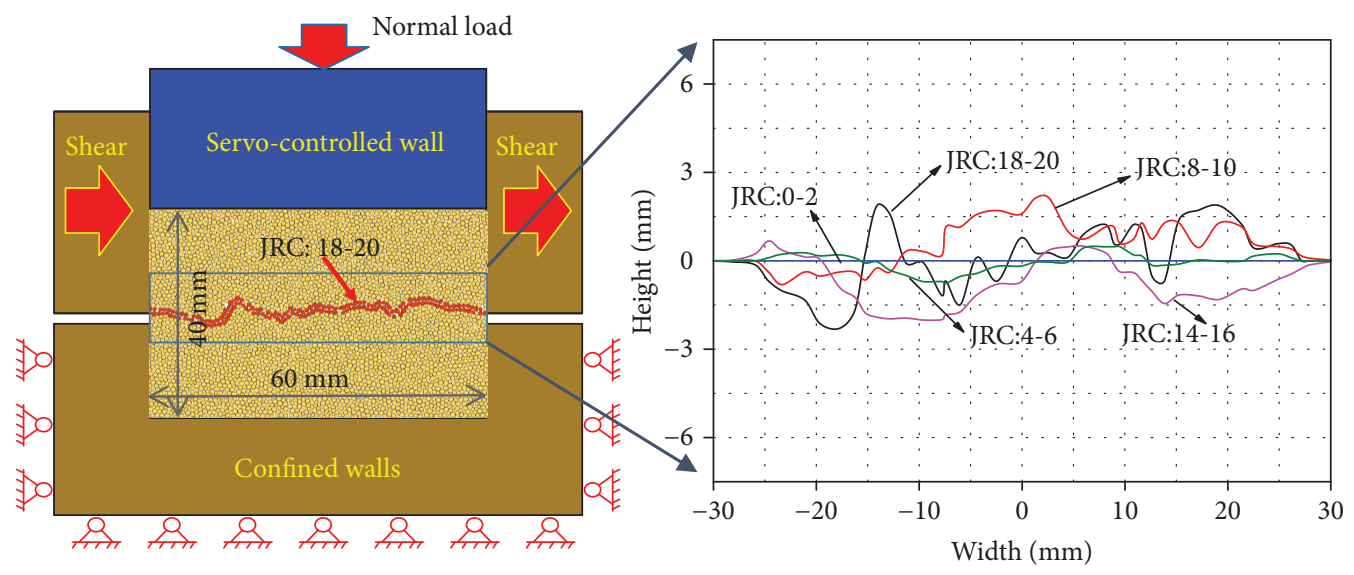

(a)

(b)

Figure 3: Simulation design and distribution of infill profiles with different joint rough coefficients (JRCs). (a) The height and width of the simulated specimens are $40 \mathrm{~mm}$ and $60 \mathrm{~mm}$, respectively. The upper half of the specimen moved to the right at a constant shear rate, while the lower part was confined by the servo-controlled wall to maintain the constant normal stress. (b) Profiles of the employed JRCs.

TABLE 2: Simulation parameters.

\begin{tabular}{lccccc}
\hline Group & Specimens number & JRC & Infill thickness ratio $t / h$ & Shear rate $(\mathrm{mm} / \mathrm{s})$ & Normal stress $(\mathrm{MPa})$ \\
\hline T1 & T1-1 T1-5 & $0-2$ & $0.02,0.05,0.10,0.15,0.20$ & 0.1 & 20 \\
T2 & T2-1 T2-5 & $4-6$ & $0.02,0.05,0.10,0.15,0.20$ & 0.1 & 20 \\
T3 & T3-1 T3-5 & $8-10$ & $0.02,0.05,0.10,0.15,0.20$ & 0.1 & 20 \\
T4 & T4-1 T4-5 & $14-16$ & $0.02,0.05,0.10,0.15,0.20$ & 0.1 & 20 \\
T5 & T5-1 T5-5 & $18-20$ & $0.02,0.05,0.10,0.15,0.20$ & 0.1 & 20 \\
\hline
\end{tabular}

compacted, and five typical JRCs (i.e., $0-2,4-6,8-10,14-16$, and 18-20) and five infill thickness ratios ranging from 0.02 to 0.2 were considered (Figure $3(\mathrm{~b})$ ). The simulation parameters are listed in Table 2. Figure 4 shows several assembled specimens with variable roughness and infill thickness.

The simulated specimens were compacted and tested as follows: (1) generation of rock specimens, (2) identification of the roughed infill with a certain thickness and JRC, (3) removal of floating particles, (4) application of a linear parallel contact bond to the intact rock and fill, (5) application of a constant normal stress of $20 \mathrm{MPa}$ on the wall using the servo control algorithm in all numerical runs, (6) shearing of the upper half using a shear rate of $0.1 \mathrm{~mm} / \mathrm{s}$, and (7) termination of the shearing process when a shear strain of 0.10 is reached. During the shearing process, mechanical and physical parameters (e.g., shear stress and porosity) were recorded in real time.

\section{Results and Discussion}

Our numerical simulation results indicate that evolution of the shear strength and permeability of rock joints is strongly related to the infill thickness ratio $(t / h)$ and JRC. Section 4.1 describes the effect of the thickness ratio on the shear behavior of infilled joints, and Section 4.2 demonstrates 


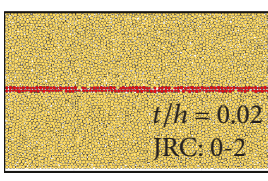

$(\mathrm{a}-1)$

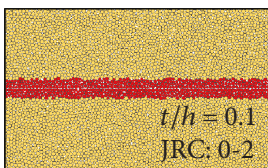

$(\mathrm{a}-2)$

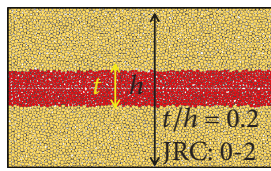

$(\mathrm{a}-3)$

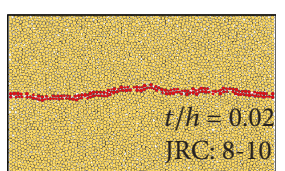

(b-1)

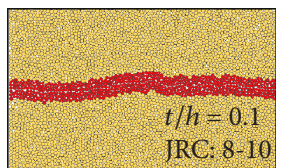

(b-2)

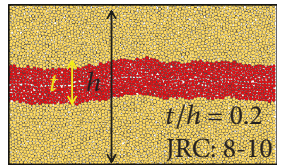

(b-3)

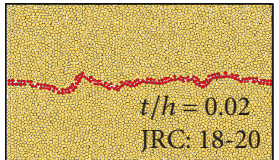

(c-1)

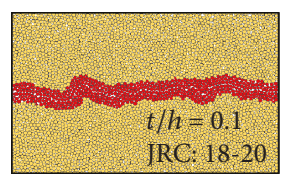

(c-2)

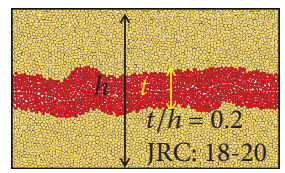

(c-3)
Figure 4: Typical infill distributions of the simulated specimens. (a-1)-(a-3) Specimens with an equal JRC of $0-2$ and infill thickness ratios $(t / h)$ of $0.02,0.1$, and 0.2 , respectively. (b-1)-(b-3) Specimens with an equal JRC of $8-10$ and $t / h$ of $0.02,0.1$, and 0.2 , respectively. (c-1)-(c-3) Specimens with an equal JRC of 18-20 and $t / h$ of $0.02,0.1$ and 0.2 , respectively.

the coupled effects of the thickness ratio and JRC on the permeability evolution.

\subsection{Effect of th on the Shear Behavior of Infilled Joints}

4.1.1. Peak and Residual Shear Strength. Figure 5 illustrates shear stress-shear strain curves of infilled specimens with various thickness ratios and JRCs. Shear behavior near the peak shear strength is shown in the magnified plots, i.e., Figures 5(a-2)-5(e-2). Prior to the peak shear strength, elastic and yield stages increase quickly, and the shear stress-shear strain curves undergo a gradual decline after reaching the peak strength.

As can been seen in Figures 5(a-2)-5(e-2), a greater infill thickness ratio implies a higher peak shear strain. Similarly, the residual shear strength increases with the infill thickness ratio. However, the residual shear strengths are similar after a relative high thickness ratio is exceeded (e.g., $t / h=0.10$ ). The shear strength is therefore predominantly governed by the infill and trends toward a stable value [26].

Peak and residual shear strengths are plotted in Figures 6(a) and 6(b), respectively, and the simulated data are listed in Table 3. A higher thickness ratio clearly implies a smaller peak shear strength, which is consistent with previous studies [22, 23, 61]. A critical thickness of 0.05 divides the peak shear strength versus thickness ratio curves into two stages. Prior to the critical value, the peak shear strength drops sharply with increasing thickness ratio, while a slight decrease can be identified afterwards. Interestingly, a higher residual shear strength, corresponding to a greater thickness ratio, is observed before reaching a critical thickness ratio of 0.10 .

4.1.2. Peak Shear Strength Model. Infilled material in joints can reduce the peak shear strength of rock masses. More
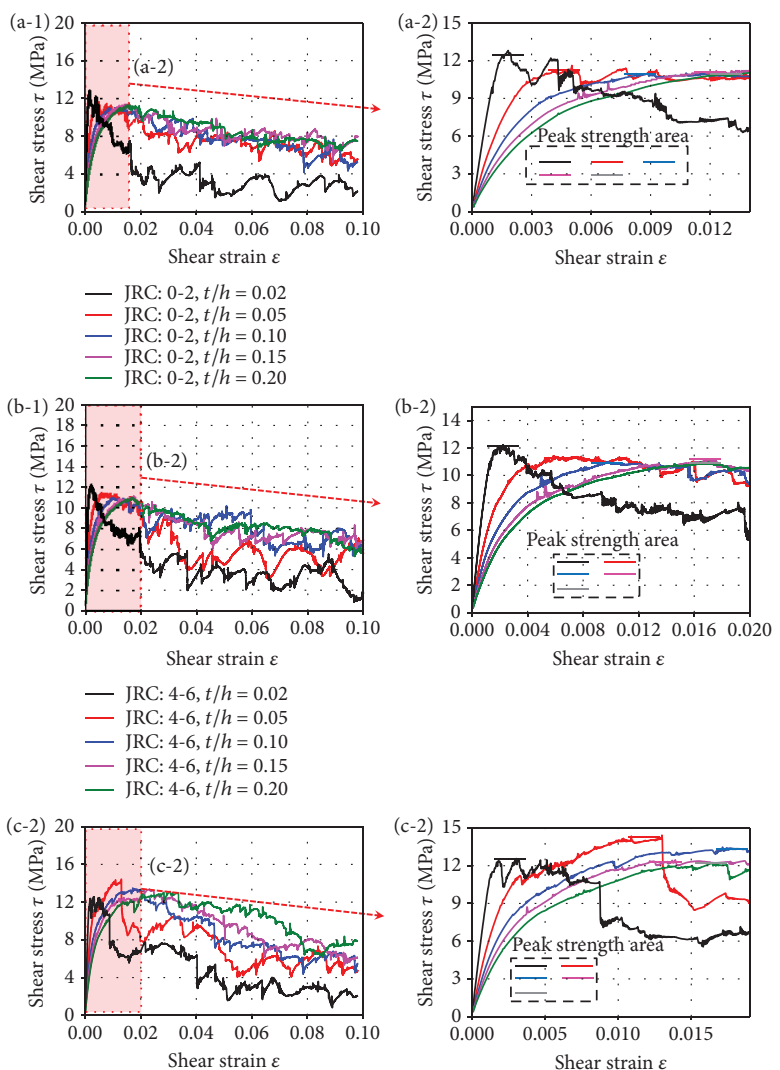

Shear strain $\varepsilon$

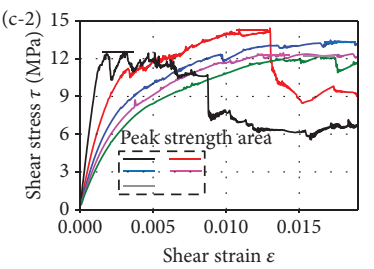

- JRC: $8-10, t / h=0.02$

- JRC: $8-10, t / h=0.05$

- JRC: $8-10, t / h=0.10$

- JRC: $8-10, t / h=0.15$

- JRC: $8-10, t / h=0.20$
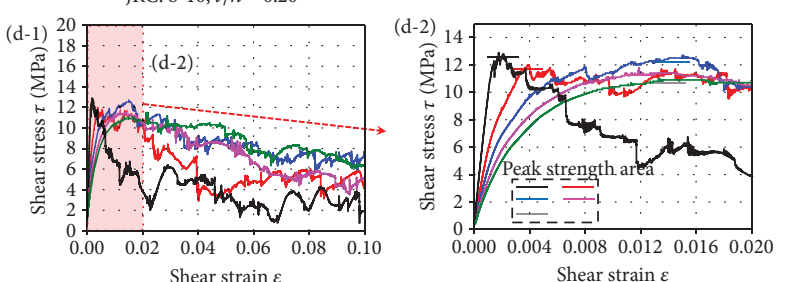

- JRC: $14-16, t / h=0.02$

- JRC: $14-16, t / h=0.05$

- JRC: $14-16, t / h=0.10$

- JRC: $14-16, t / h=0.15$

- JRC: $14-16, t / h=0.20$
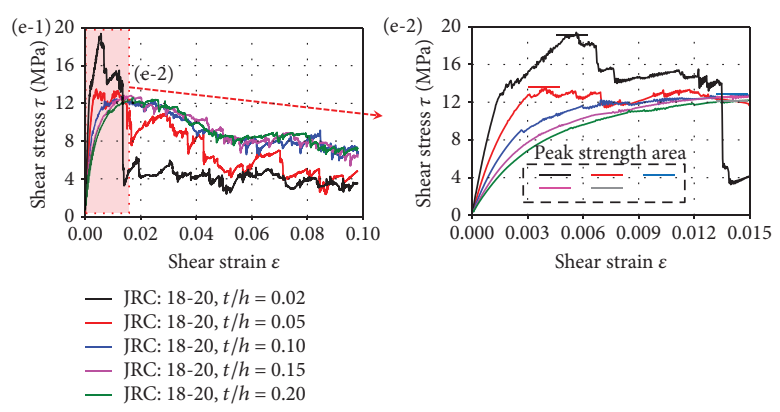

FIGURE 5: Shear stress-shear strain curves and peak shear strengths of simulated specimens. Panels (a-1), (b-1), (c-1), (d-1), and (e-1) are shear stress-shear strain curves of the infilled joints with JRCs of $0-2,4-6,8-10,14-16$, and 18-20, respectively. Panels (a-2), (b-2), (c-2), (d-2), and (e-2) are peak shear strengths of the simulated specimens derived from panels (a-1), (b-1), (c-1), (d-1), and (e-1), respectively. 


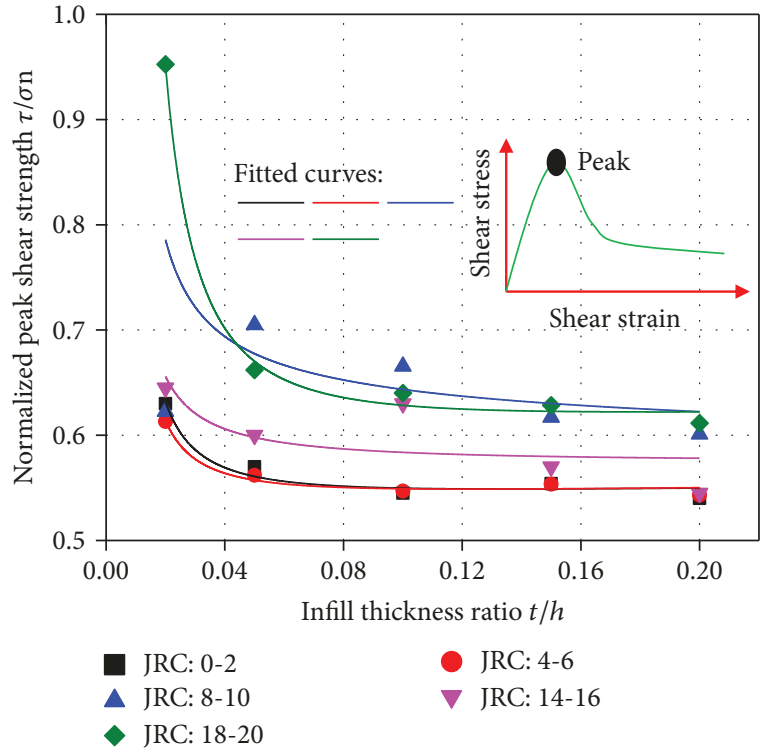

(a)

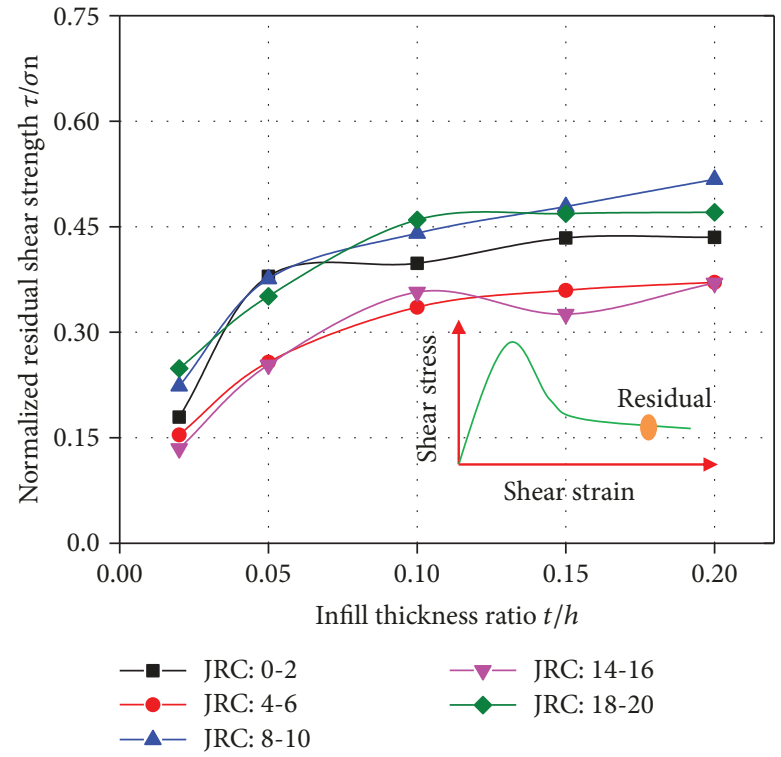

(b)

FIgURE 6: Relation between the infill thickness ratio and normalized shear and residual strengths. (a) Normalized peak shear strength versus thickness ratio. (b) Normalized residual shear strength versus thickness ratio.

TABLE 3: Normalized peak and residual shear strengths.

\begin{tabular}{|c|c|c|c|c|c|c|c|c|c|c|}
\hline \multirow{3}{*}{ Thickness } & \multicolumn{5}{|c|}{ Normalized peak shear strength } & \multicolumn{5}{|c|}{ Normalized residual shear strength } \\
\hline & & & JRC & & & & & JRC & & \\
\hline & $0-2$ & $4-6$ & $8-10$ & $14-16$ & $18-20$ & $0-2$ & $4-6$ & $8-10$ & $14-16$ & $18-20$ \\
\hline 0.02 & 0.63 & 0.615 & 0.625 & 0.645 & 0.955 & 0.18 & 0.155 & 0.225 & 0.135 & 0.25 \\
\hline 0.05 & 0.57 & 0.562 & 0.705 & 0.6 & 0.66 & 0.38 & 0.26 & 0.375 & 0.255 & 0.35 \\
\hline 0.1 & 0.545 & 0.545 & 0.665 & 0.63 & 0.64 & 0.4 & 0.335 & 0.44 & 0.355 & 0.46 \\
\hline 0.15 & 0.555 & 0.56 & 0.615 & 0.57 & 0.63 & 0.435 & 0.36 & 0.48 & 0.325 & 0.47 \\
\hline 0.2 & 0.54 & 0.545 & 0.6 & 0.545 & 0.61 & 0.435 & 0.37 & 0.515 & 0.37 & 0.47 \\
\hline
\end{tabular}

specifically, a thicker infill implies a smaller shear strength $[23,24]$. The relationship between shear strength and thickness ratio can be expressed by the following function [26]:

$$
\begin{aligned}
\left(\frac{\tau}{\sigma_{n}}\right)_{\text {filled }} & =\frac{\left(\tau / \sigma_{n}\right)_{\text {clean or unfilled }}+\Delta \tau}{\sigma_{n}}, \\
\frac{\Delta \tau}{\sigma_{n}} & =\frac{(t / a)}{[\alpha(t / a)+\beta]},
\end{aligned}
$$

where $\tau / \sigma_{n}$ is the normalized shear strength of the infilled or unfilled rock joints, $\Delta \tau$ is the variation of the stress (MPa), $\sigma_{n}$ is the normal load (MPa), $t$ is the thickness of the infill $(\mathrm{m})$, and $a$ refers to the height of the rock $(\mathrm{m})$ and is a constant. $\alpha$ and $\beta$ are constants that depend on the normal load and surface roughness, and their magnitudes can be obtained by a regression of the simulated data.

According to the hyperbolic function, Indraratna et al. [24] developed a conceptual normalized shear strength model for infilled joints that can be expressed as

$$
\begin{aligned}
\frac{\tau}{\sigma_{n}}= & \tan \left(\phi_{p}\right) \times\left(1-m \times \frac{t}{t_{c r}}\right)^{a}+\tan \left(\phi_{f}\right) \\
& \times\left[\frac{2}{\left(1+t_{c r} / t / m\right)}\right]^{b},
\end{aligned}
$$

where $\varphi_{p}$ is the friction angle of intact rock, $k_{c r}$ is the ratio of infill thickness to the critical thickness $\left(k_{c r}=t / t_{c r}\right), \varphi_{f}$ is the friction angle of the infilling material, and $m, a$, and $b$ are constants. Curves fitted according to equation (8) and key regressive parameters are presented in Figure 6(a). The mechanical parameters are listed in Table 3.

\subsection{Coupled Effects of t/h and JRC on the Permeability Evolution of Infilled Joints}

4.2.1. Permeability Evolution. Dilation or compaction usually occur during the direct shear test $[31,62]$ and can have a substantial effect on the permeability evolution of an infilled rock mass, which can be directly measured in physical experiments by monitoring change in specimen layer 


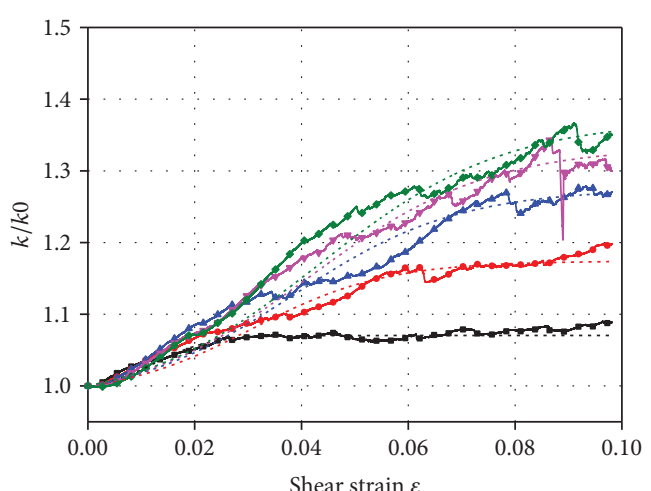

Shear strain $\varepsilon$

- JRC: $0-2, t / h=0.02 \quad-$ Fitted curve $t / h=0.02$

- JRC: $0-2, t / h=0.05 \quad--$ Fitted curve $t / h=0.05$

- JRC: $0-2, t / h=0.10 \quad--$ Fitted curve $t / h=0.10$

$\rightarrow$ JRC: $0-2, t / h=0.15 \quad--$ Fitted curve $t / h=0.15$

- JRC: $0-2, t / h=0.20 \quad--$ Fitted curve $t / h=0.20$

(a)

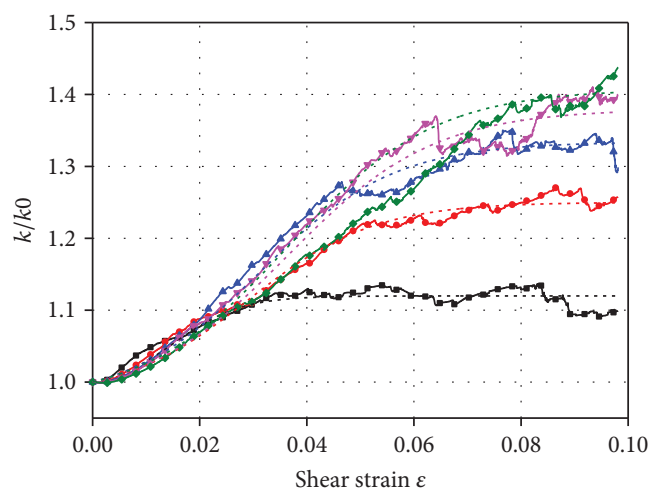

- JRC: $8-10, t / h=0.02 \quad--$ Fitted curve $t / h=0.02$

- JRC: $8-10, t / h=0.05 \quad--$ Fitted curve $t / h=0.05$

- JRC: $8-10, t / h=0.10 \quad$ - - Fitted curve $t / h=0.10$

$\neg$ JRC: $8-10, t / h=0.15 \quad--$ Fitted curve $t / h=0.15$

JRC: $8-10, t / h=0.20 \quad--$ Fitted curve $t / h=0.20$

(c)

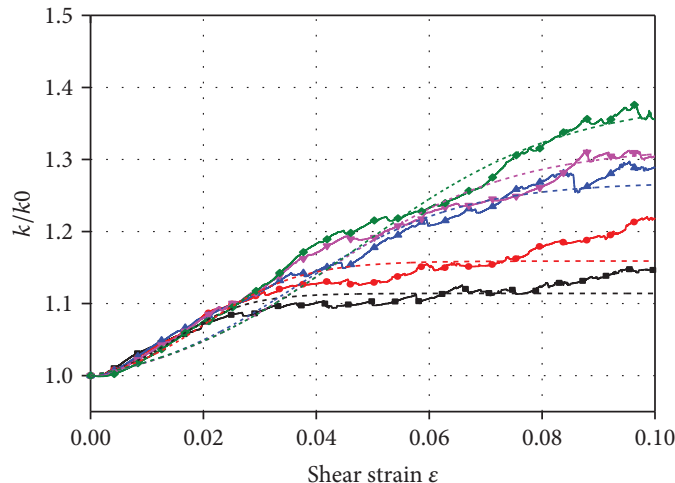

- JRC: $4-6, t / h=0.02 \quad--$ Fitted curve $t / h=0.02$

- JRC: $4-6, t / h=0.05 \quad--$ Fitted curve $t / h=0.05$

- JRC: $4-6, t / h=0.10 \quad$ - - Fitted curve $t / h=0.10$

$\rightarrow$ JRC: $4-6, t / h=0.15 \quad--$ Fitted curve $t / h=0.15$

JRC: $4-6, t / h=0.20 \quad--$ Fitted curve $t / h=0.20$

(b)

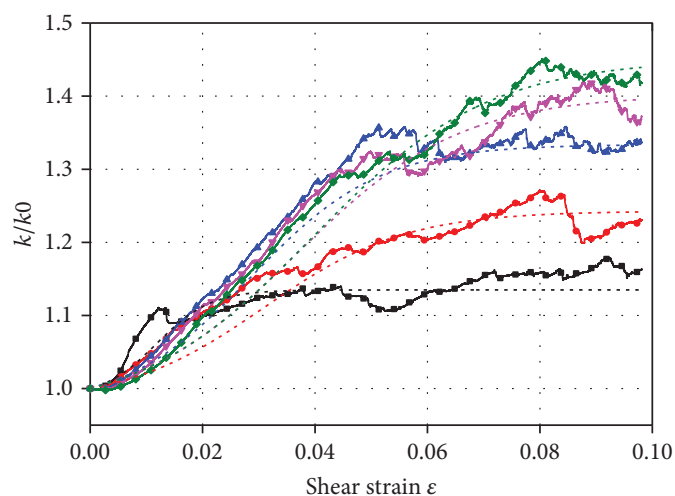

- JRC: $14-16, t / h=0.02 \quad--$ Fitted curve $t / h=0.02$

JRC: $14-16, t / h=0.05 \quad--$ Fitted curve $t / h=0.05$

JRC: $14-16, t / h=0.10 \quad--$ Fitted curve $t / h=0.10$

JRC: $14-16, t / h=0.15 \quad--$ Fitted curve $t / h=0.15$

JRC: $14-16, t / h=0.20 \quad--$ Fitted curve $t / h=0.20$

(d)

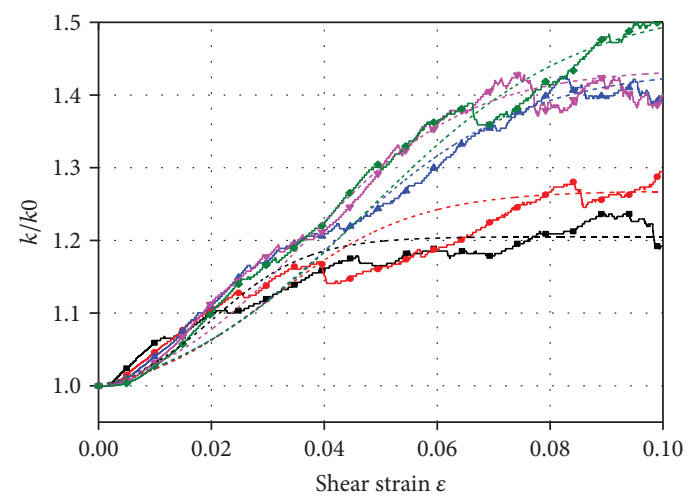

- JRC: $18-20, t / h=0.02 \quad \ldots$ Fitted curve $t / h=0.02$

- JRC: $18-20, t / h=0.05 \quad--$ Fitted curve $t / h=0.05$

- JRC: $18-20, t / h=0.10 \quad--$ Fitted curve $t / h=0.10$

$\neg$ JRC: $18-20, t / h=0.15 \quad--$ Fitted curve $t / h=0.15$

JRC: $18-20, t / h=0.20 \quad--$ Fitted curve $t / h=0.20$

(e)

FIGURE 7: Typical relative difference in permeability versus shear strain with different joint roughness coefficients (JCRs) of (a) 0-2, (b) 4-6, (c) $8-10$, (d) $14-16$, and (e) 18-20. 
TABLE 4: Effect of thickness ratio $(t / h)$ and the joint roughness coefficient (JRC) on yield permeability.

\begin{tabular}{lccccc}
\hline Thickness ratio & $0-2$ & & JRC & & \\
$t / h$ & $k / k_{0}$ & $t / h$ & $k / k_{0}$ & $t / h$ & $k / k_{0}$ \\
\hline 0.02 & 1.07 & 0.02 & 1.07 & 0.02 & 1.07 \\
0.05 & 1.15 & 0.05 & 1.15 & 0.05 & 1.15 \\
0.1 & 1.24 & 0.1 & 1.24 & 0.1 & 1.24 \\
0.15 & 1.31 & 0.15 & 1.31 & 0.15 & 1.31 \\
0.2 & 1.35 & 0.2 & 1.35 & 0.2 & 1.35 \\
\hline
\end{tabular}

thickness. Although permeability and porosity are closely related, the evolution of porosity is difficult to observe during real experiments.

Assuming that the rock matrix is assumed impermeable and fluid only flows through the porous infills within the void spaces of the fracture. Permeability is normally enhanced during shear slip and dilation. To illustrate the relationship between permeability and shear strain, we employed an existing model to predict the permeability of infilled joints by iterating the derived porosity. The model proposed by Segall and Rice [63] using the test data from Marone et al. [46] indicates that permeability evolution can be estimated by either porosity or specimens thickness $[64,65]$. An estimation of the permeability can be expressed as follows:

$$
\begin{gathered}
\frac{k}{k_{0}} \cong\left(1+\frac{\Delta H}{H}\right)^{3}, \\
\frac{\Delta H}{H} \cong \Delta \phi=\phi-\phi_{0},
\end{gathered}
$$

where $k / k_{0}$ is the relative difference in permeability, $\triangle H / H$ is the relative difference in specimen thickness, and $\Delta \phi$ is the relative difference in porosity.

According to equations (9) and (10), the relative difference in permeability (for convenience, termed as permeability) can be obtained. The evolution of permeability is illustrated in Figure 7. It is clear that permeability increases approximately linearly with increasing shear strain before the yield stage is reached. However, permeability tends to maintain a stable value after the critical shear strain is attained. The thickness ratio has a key effect on the permeability of infilled rock joints. More specifically, permeability increases with the thickness ratio. The simulated data are included in Table 4.

As shown in Figure 7, permeability increases rapidly with shear strain before the yield stage is reached, during which the permeability trends to a constant value. The relation between the relative difference in permeability and shear displacement can be represented by a sigmoidal logarithmic function as shown in equation (6). The calibrated curves are plotted in Figure 7. The regressive curves show good agreement with the simulated results. In addition, the increasing stage, yield stage, and stable stage are also well illustrated.

\subsubsection{Effects of $t / h$ and JRC on Permeability Evolution.} Figure 8 and Table 4 show the effects of the JRC and thickness ratio on the relative difference in permeability. It is clear that permeability increases with both $t / h$ and JRC. In the permeability versus thickness ratio curves, permeability increases rapidly at first; however, the growth ratio then decreases gradually after the peak permeability is reached. This result is consistent with the findings by Marone et al. [46].

Permeability increases with both the thickness ratio and JRC, which may be explained by the following two reasons. Firstly, loose media in joints can be assumed as tectonically crushed rock materials or the product of the decomposition or joint weathering, and the bond strength between joint surfaces is zero $[23,24]$. The particles of infilled materials are unbonded but can still resist one another through surface friction, which means that these particles would be rearranged throughout the entire test. This rearrangement is affected by the applied normal stress and joint roughness. The rearrangement activity would be more intense with a thicker infill, which may result in a larger porosity variation as particles mechanically degrade one another. Secondly, as can be seen from Figure 8(b), a higher JRC corresponding to greater permeability due to greater joint dilation can be expected with a relatively higher JRC.

\section{Conclusions}

In this paper, the coupled effects of JRC and sand-infilled thickness on the shear behavior and permeability evolution were studied by conducting numerical simulations using PFC2D. Five groups of JRCs were adopted to represent joints with different roughness, and five groups of infill thickness ratios were used to study the impact of infill thickness on the shear behavior and permeability evolution. Several important conclusions can be drawn.

(1) Peak and residual shear strength were determined in the simulated direct shear tests, and the effects of the infill thickness are significant. The peak shear strength decreases with the thickness ratio in the form of a hyperbolic function. A critical thickness ratio of 0.05 divides the thickness ratio-peak shear strength curves into two stages, i.e., sharp drop stage and slight decrease stage. However, the residual shear strength increases with the thickness ratio before a critical thickness ratio is reached, after which point the residual shear strength trends toward a constant value

(2) The permeability evolution during a direct shear test can be estimated using the relative porosity difference. Permeability is enhanced by increasing shear strain, and a sigmoidal logarithmic function can be employed to illustrate their relationship 


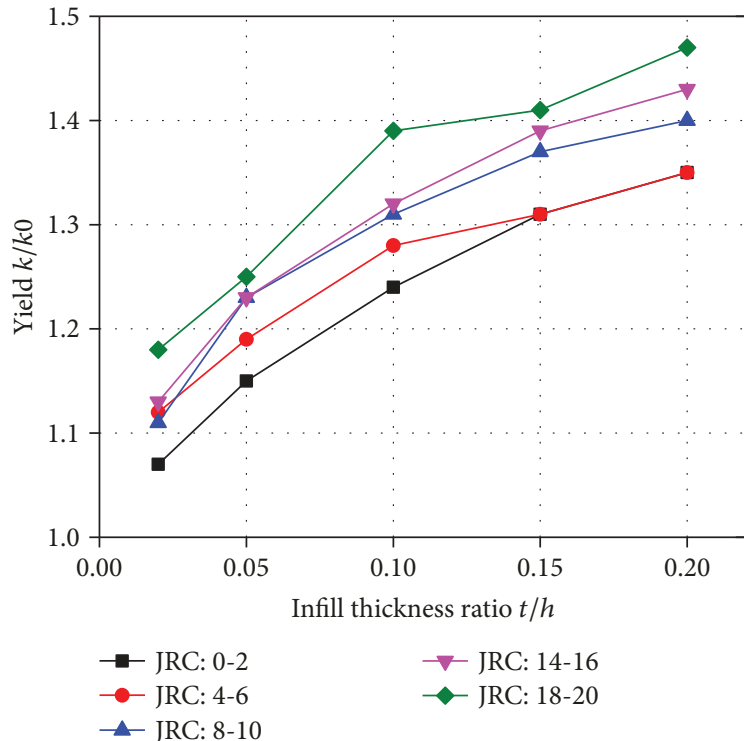

(a)

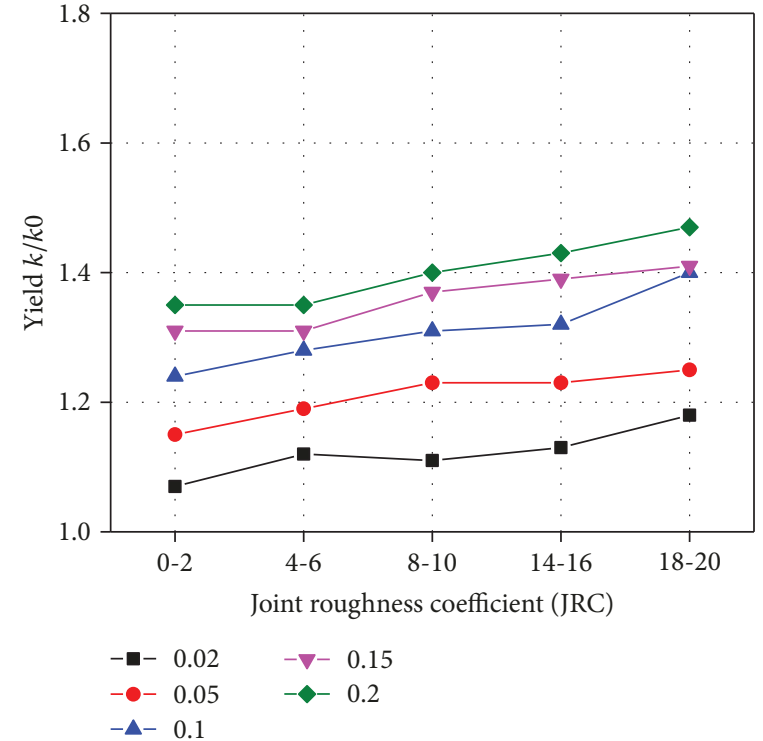

(b)

FIgURE 8: Effects of the (a) thickness ratio $(t / h)$ and (b) joint roughness coefficient (JRC) on permeability evolution.

(3) The thickness ratio and JRC have coupled effects on the permeability evolution of infilled rock joints. More specifically, permeability increases with both the thickness ratio $(t / h)$ and JRC. The permeability versus thickness ratio curves show that permeability increases significantly at first; however, the growth ratio decreases gradually when the thickness ratio reaches a critical value

\section{Data Availability}

The data used to support the findings of this study are included within the article.

\section{Conflicts of Interest}

The authors declare that there is no conflict of interest regarding the publication of this paper.

\section{Authors' Contributions}

Hongwei Zhang contributed equally to this work.

\section{Acknowledgments}

This study was supported by the National Natural Science Foundation of China (grant numbers 51604267, 51674242), the State Key Laboratory of Coal Resources and Safe Mining, CUMT (grant number SKLCRSM15X05), and the Fundamental Research Funds for the Central Universities (grant number 2017XKZD06).

\section{References}

[1] C. A. Barton, M. D. Zoback, and D. Moos, "Fluid flow along potentially active faults in crystalline rock," Geology, vol. 23, no. 8, pp. 683-686, 1995.

[2] R. H. Sibson, "Structural permeability of fluid-driven faultfracture meshes," Journal of Structural Geology, vol. 18, no. 8, pp. 1031-1042, 1996.

[3] W. Wang, H. Wang, D. Li, H. Li, and Z. Liu, "Strength and failure characteristics of natural and water-saturated coal specimens under static and dynamic loads," Shock and Vibration, vol. 2018, Article ID 3526121, 15 pages, 2018.

[4] S. M. Odumabo and Z. T. Karpyn, "Investigation of gas flow hindrance due to fracturing fluid leakoff in low permeability sandstones," Journal of Natural Gas Science and Engineering, vol. 17, pp. 1-12, 2014.

[5] N. E. Odling, P. Gillespie, B. Bourgine et al., "Variations in fracture system geometry and their implications for fluid flow in fractures hydrocarbon reservoirs," Petroleum Geoscience, vol. 5, no. 4, pp. 373-384, 1999.

[6] D. Elsworth, C. J. Spiers, and A. R. Niemeijer, "Understanding induced seismicity," Science, vol. 354, no. 6318, pp. 1380-1381, 2016.

[7] Q. Lei, J.-P. Latham, and C.-F. Tsang, "The use of discrete fracture networks for modelling coupled geomechanical and hydrological behaviour of fractured rocks," Computers and Geotechnics, vol. 85, pp. 151-176, 2017.

[8] W. Li and A. Sakhaee-Pour, "Two-scale geomechanics of carbonates," Rock Mechanics and Rock Engineering, vol. 51, no. 12, pp. 3667-3679, 2018.

[9] A. Sakhaee-Pour and W. Li, "Two-scale geomechanics of shale," SPE Reservoir Evaluation \& Engineering, 2018.

[10] S. J. Bauer, K. Huang, Q. Chen, A. Ghassemi, and P. Barrow, Laboratory and Numerical Evaluation of EGS Shear Stimulation, Sandia National Laboratories (SNL-NM), Albuquerque, NM, USA, 2016. 
[11] J. Pogacnik, D. Elsworth, M. O’Sullivan, and J. O’Sullivan, "A damage mechanics approach to the simulation of hydraulic fracturing/shearing around a geothermal injection well," Computers and Geotechnics, vol. 71, pp. 338-351, 2015.

[12] M. McClure and R. Horne, "Conditions required for shear stimulation in EGS," Proceedings of the 2013 European Geothermal Congress, Pisa, Italy, 2013.

[13] C. H. Scholz, The Mechanics of Earthquakes and Faulting, Cambridge university press, 2002.

[14] F. M. Chester and J. M. Logan, "Implications for mechanical properties of brittle faults from observations of the punchbowl fault zone, California," Pure and Applied Geophysics, vol. 124, no. 1-2, pp. 79-106, 1986.

[15] P. Segall and D. D. Pollard, "Nucleation and growth of strike slip faults in granite," Journal of Geophysical Research Solid Earth, vol. 88, no. B1, pp. 555-568, 1983.

[16] Z. Ye, V. Sesetty, and A. Ghassemi, "Experimental and numerical investigation of shear stimulation and permeability evolution in shales," in SPE Hydraulic Fracturing Technology Conference and Exhibition, Woodlands, Texas, USA, January 2018.

[17] Z. Ye and A. Ghassemi, "Experimental study on injectioninduced fracture propagation and coalescence for EGS stimulation," in Proceeding: 43rd Workshop on Geothermal Reservoir Engineering, Stanford, California, USA, 2018.

[18] Z. Ye, A. Ghassemi, and S. Riley, "Stimulation mechanisms in unconventional reservoirs," in Proceedings of the 6th Unconventional Resources Technology Conference, Houston, TX, USA, 2018.

[19] J. C. Jaeger, "Friction of rocks and stability of rock slopes," Géotechnique, vol. 21, no. 2, pp. 97-134, 1971.

[20] E. Hoek, "Strength of jointed rock masses," Géotechnique, vol. 33, no. 3, pp. 187-223, 1983.

[21] B. Ladanyi and G. Archambault, "Shear strength and deformability of filled indented joints," in International Symposium on the Geotechnics of Structurally Complex Formations, pp. 317-326, Capri, 1977.

[22] P. De Toledo and M. De Freitas, "Discussion: laboratory testing and parameters controlling the shear strength of filled rock joints," Géotechnique, vol. 45, no. 1, pp. 175-183, 1995.

[23] D. A. F. Oliveira, B. Indraratna, and J. Nemcik, "Critical review on shear strength models for soil-infilled joints," Geomechanics and Geoengineering, vol. 4, no. 3, pp. 237-244, 2009.

[24] B. Indraratna, M. Jayanathan, and T. Brown, "Shear strength model for overconsolidated clay-infilled idealised rock joints," Géotechnique, vol. 58, no. 1, pp. 55-65, 2008.

[25] B. Indraratna, A. Haque, and N. Aziz, "Laboratory modelling of shear behaviour of soft joints under constant normal stiffness conditions," Geotechnical and Geological Engineering, vol. 16, no. 1, pp. 17-44, 1998.

[26] B. Indraratna, N. Aziz, and A. Haque, "Shear behaviour of idealized infilled joints under constant normal stiffness," Géotechnique, vol. 49, no. 3, pp. 331-355, 1999.

[27] M. Jayanathan and B. Indraratna, "Measurement of pore water pressure of clay-infilled rock joints during triaxial shearing," Géotechnique, vol. 55, no. 10, pp. 759-764, 2005.

[28] H. Jahanian and M. H. Sadaghiani, "Experimental study on the shear strength of sandy clay infilled regular rough rock joints," Rock Mechanics and Rock Engineering, vol. 48, no. 3, pp. 907922, 2015.
[29] M. Karakus, Y. Liu, G. Zhang, and H. Tang, "A new shear strength model incorporating influence of infill materials for rock joints," Geomechanics and Geophysics for Geo-Energy and Geo-Resources, vol. 2, no. 3, pp. 183-193, 2016.

[30] N. Barton, "Review of a new shear-strength criterion for rock joints," Engineering Geology, vol. 7, pp. 287-332, 1974.

[31] N. Barton and V. Choubey, "The shear strength of rock joints in theory and practice," Rock Mechanics, vol. 10, no. 1-2, pp. 1-54, 1977.

[32] J. Zhao, "Joint surface matching and shear strength part B: JRC-JMC shear strength criterion," International Journal of Rock Mechanics and Mining Sciences, vol. 34, no. 2, pp. 179185, 1997.

[33] C. C. Xia, Z. C. Tang, W. M. Xiao, and Y. L. Song, "New peak shear strength criterion of rock joints based on quantified surface description," Rock Mechanics and Rock Engineering, vol. 47, no. 2, pp. 387-400, 2014.

[34] P. H. S. W. Kulatilake, G. Shou, and T. H. Huang, "Spectralbased peak-shear-strength criterion for rock joints," Journal of Geotechnical Engineering, vol. 121, no. 11, pp. 789-796, 1995.

[35] Y. Ohnishi and P. Dharmaratne, "Shear behaviour of physical models of rock joints under constant normal stiffness conditions," in International Symposium on Rock Joints, Loen, Norway, June 1990.

[36] J. W. Park and J. J. Song, "Numerical simulation of a direct shear test on a rock joint using a bonded-particle model," International Journal of Rock Mechanics and Mining Sciences, vol. 46, no. 8, pp. 1315-1328, 2009.

[37] N. Babanouri, S. K. Nasab, A. Baghbanan, and H. R. Mohamadi, "Over-consolidation effect on shear behavior of rock joints," International Journal of Rock Mechanics and Mining Sciences, vol. 48, no. 8, pp. 1283-1291, 2011.

[38] P. A. Cundall, "Numerical experiments on rough joints in shear using a bonded particle model," in Aspects of Tectonic Faulting, F. K. Lehner and J. L. Urai, Eds., Springer, Berlin Heidelberg, 2000.

[39] Y. Jiang, B. Li, and Y. Tanabashi, "Estimating the relation between surface roughness and mechanical properties of rock joints," International Journal of Rock Mechanics and Mining Sciences, vol. 43, no. 6, pp. 837-846, 2006.

[40] R. Olsson and N. Barton, "An improved model for hydromechanical coupling during shearing of rock joints," International Journal of Rock Mechanics and Mining Sciences, vol. 38, no. 3, pp. 317-329, 2001.

[41] L. Xu and N. Xie, "Test and theoretical research on permeability characteristics of shear fracture in rock mass," Chinese Journal of Rock Mechanics and Engineering, vol. 28, pp. 2249-2257, 2009.

[42] L. Xue and S. Chen, "Coupling analysis of seepage and stressstrain of rock fracture during shear process," Chinese Journal of Rock Mechanics and Engineering, vol. 26, pp. 3913-3919, 2007.

[43] V. Rasouli and A. Hosseinian, "Correlations developed for estimation of hydraulic parameters of rough fractures through the simulation of JRC flow channels," Rock Mechanics and Rock Engineering, vol. 44, no. 4, pp. 447-461, 2011.

[44] H. S. Lee and T. F. Cho, "Hydraulic characteristics of rough fractures in linear flow under normal and shear load," Rock Mechanics and Rock Engineering, vol. 35, no. 4, pp. 299-318, 2002. 
[45] T. Esaki, S. Du, Y. Mitani, K. Ikusada, and L. Jing, "Development of a shear-flow test apparatus and determination of coupled properties for a single rock joint," International Journal of Rock Mechanics and Mining Sciences, vol. 36, no. 5, pp. 641-650, 1999.

[46] C. Marone, C. B. Raleigh, and C. H. Scholz, "Frictional behavior and constitutive modeling of simulated fault gouge," Journal of Geophysical Research Solid Earth, vol. 95, no. B5, pp. 7007-7025, 1990.

[47] M. Wei, J. Liu, X. Feng et al., "Quantitative study on coal permeability evolution with consideration of shear dilation," Journal of Natural Gas Science \& Engineering, vol. 36, pp. 1199-1207, 2016.

[48] Y. Jiang, W. Gang, L. I. Bo, and X. Zhao, "Experimental study and analysis of shear-flow coupling behaviors of rock joints," Chinese Journal of Rock Mechanics and Engineering, vol. 26, pp. 2253-2259, 2007.

[49] X. Xie, Y. Zheng, and M. Zhang, "Study of relationship between rock mass deformation and permeability evolvement," Chinese Journal of Rock Mechanics and Engineering, vol. 28, no. z1, pp. 2657-2661, 2009.

[50] S. Jon, E. Derek, and M. Chris, "Shear-induced dilatancy of fluid-saturated faults: experiment and theory," Journal of Geophysical Research Atmospheres, vol. 114, no. B12, article B12404, 2009.

[51] Z. Zhang and J. Nemcik, "Friction factor of water flow through rough rock fractures," Rock Mechanics and Rock Engineering, vol. 46, no. 5, pp. 1125-1134, 2013.

[52] I. W. Yeo, M. H. D. Freitas, and R. W. Zimmerman, "Effect of shear displacement on the aperture and permeability of a rock fracture," International Journal of Rock Mechanics and Mining Sciences, vol. 35, no. 8, pp. 1051-1070, 1998.

[53] M. H. Mehranpour and P. H. S. W. Kulatilake, "Improvements for the smooth joint contact model of the particle flow code and Its applications," Computers and Geotechnics, vol. 87, pp. 163-177, 2017.

[54] Itasca Consulting Group Inc., PFC (Particle Flow Code in 2 and 3 Dimensions), Version 5.0 [User's Manual], Minneapolis, USA, 2014.

[55] M. Bahaaddini, G. Sharrock, and B. K. Hebblewhite, "Numerical direct shear tests to model the shear behaviour of rock joints," Computers and Geotechnics, vol. 51, pp. 101-115, 2013.

[56] D. O. Potyondy and P. A. Cundall, "A bonded-particle model for rock," International Journal of Rock Mechanics and Mining Sciences, vol. 41, no. 8, pp. 1329-1364, 2004.

[57] N. Cho, C. D. Martin, and D. C. Sego, "A clumped particle model for rock," International Journal of Rock Mechanics and Mining Sciences, vol. 44, no. 7, pp. 997-1010, 2007.

[58] J. Yoon, "Application of experimental design and optimization to PCF model calibration in uniaxial compression simulation," International Journal of Rock Mechanics and Mining Sciences, vol. 44, no. 6, pp. 871-889, 2007.

[59] D. O. Potyondy, "Simulating stress corrosion with a bondedparticle model for rock," International Journal of Rock Mechanics and Mining Sciences, vol. 44, no. 5, pp. 677-691, 2007.

[60] D. Dempsey, S. Kelkar, K. Lewis et al., "Modeling shear stimulation of the Desert Peak EGS well 27-15 using a coupled thermal-hydrological-mechanical simulator," in 47th U.S. Rock Mechanics/Geomechanics Symposium, pp. 1006-1019, San Francisco, CA, USA, June 2013.
[61] A. Khosravi, M. Khosravi, and C. L. MeehanIn, "The hydromechanical behavior of infilled rock joints with fill materials in unsaturated conditions," in Geo-Congress 2013: Stability and Performance of Slopes and Embankments III, pp. 129138, Geotechnical Special Publication, 2013.

[62] L. Zhang and C. Thornton, "A numerical examination of the direct shear test,” Géotechnique, vol. 57, no. 4, pp. 343-354, 2007.

[63] P. Segall and J. R. Rice, "Dilatancy, compaction, and slip instability of a fluid-infiltrated fault," Journal of Geophysical Research: Solid Earth, vol. 100, no. B11, pp. 22155-22171, 1995.

[64] Z. Ouyang and D. Elsworth, "Evaluation of groundwater flow into mined panels," International Journal of Rock Mechanics and Mining Science \& Geomechanics Abstracts, vol. 30, no. 2, pp. 71-79, 1993.

[65] J. Samuelson, D. Elsworth, and C. Marone, "Influence of dilatancy on the frictional constitutive behavior of a saturated fault zone under a variety of drainage conditions," Journal of Geophysical Research: Solid Earth, vol. 116, no. B10, 2011.

[66] C. L. Kirkland, G. I. Alsop, and A. R. Prave, "The brittle evolution of a major strike-slip fault associated with granite emplacement: a case study of the Leannan Fault, NW Ireland," Journal of the Geological Society, vol. 165, no. 1, pp. 341-352, 2008. 

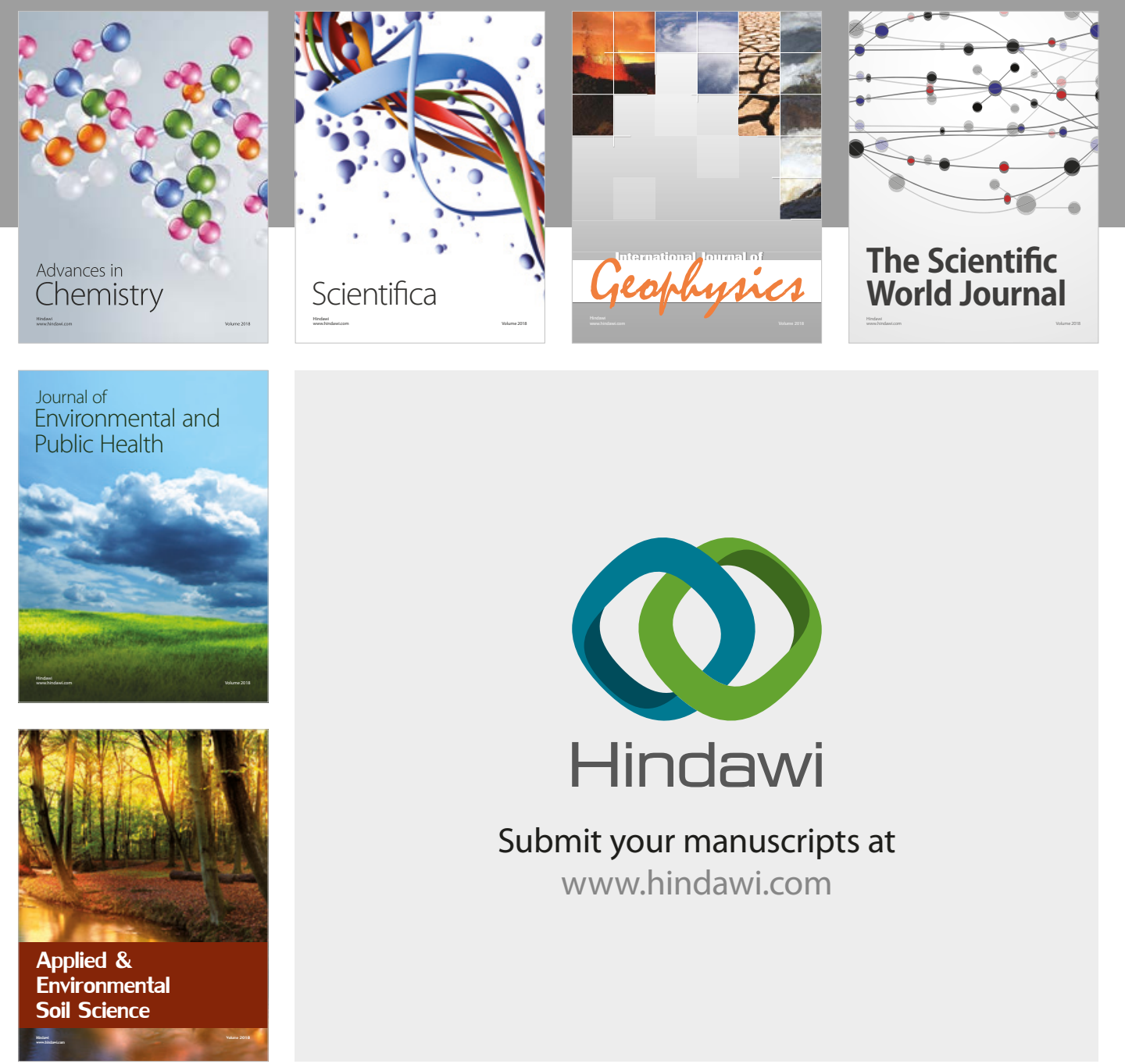

The Scientific

\section{World Journal}
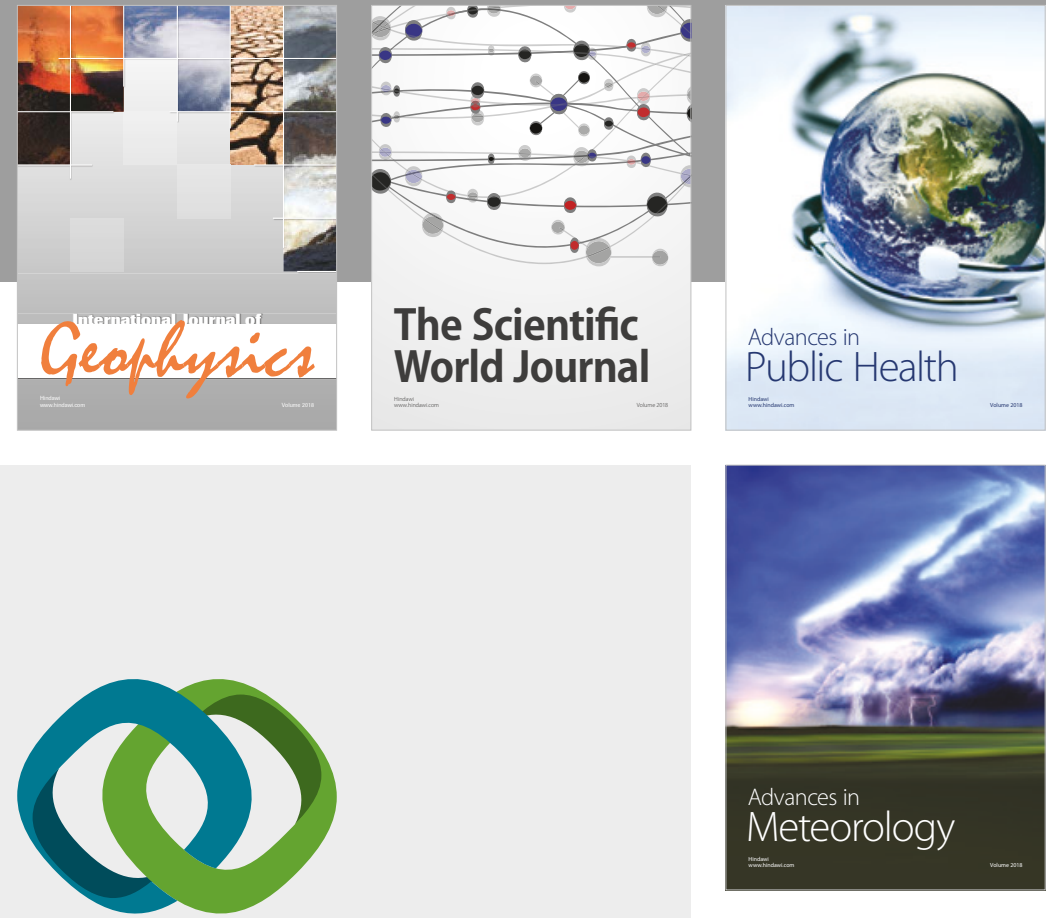

Advan

Public Health

\section{Hindawi}

Submit your manuscripts at

www.hindawi.com
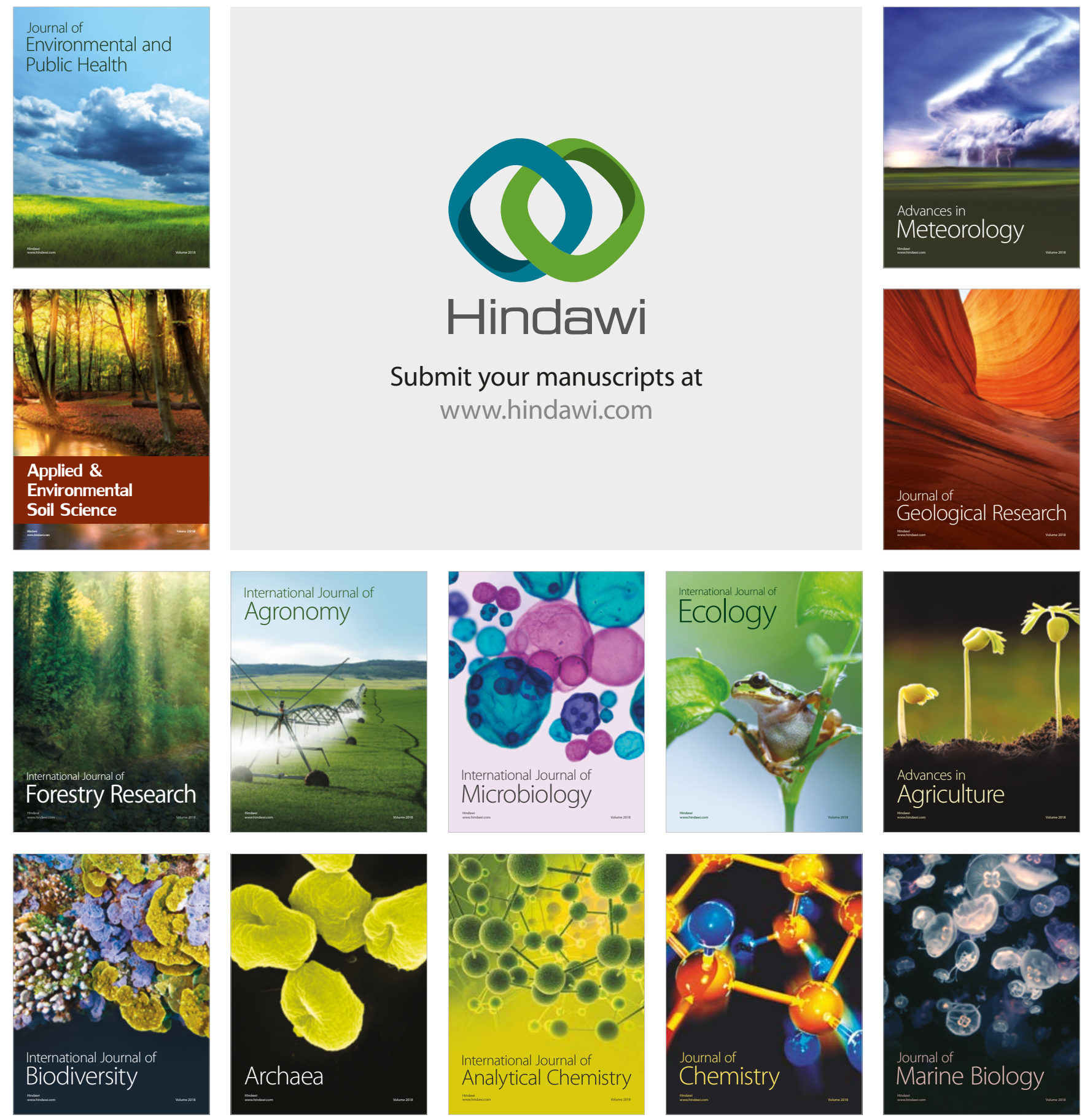